This document is the accepted manuscript version of the following article: Rizzi, S., Legriffon, I., Pieren, R., \& Bertsch, L. (2020). A comparison of aircraft flyover auralizations by the aircraft noise simulation working group. In AIAA aviation 2020 forum (AIAA 2020-2582 (16 pp.)). https:// doi.org/10.2514/6.2020-2582

\title{
A Comparison of Aircraft Flyover Auralizations by the Aircraft Noise Simulation Working Group
}

\author{
Stephen A. Rizzi ${ }^{1}$ \\ NASA Langley Research Center, Hampton, VA 23681, USA \\ Ingrid LeGriffon ${ }^{2}$ \\ ONERA - Université Paris Saclay, FR-92322 Chatillon, France \\ Reto Pieren ${ }^{3}$ \\ Empa, Swiss Federal Laboratories for Materials Science and Technology, 8600 Duebendorf, Switzerland \\ Lothar Bertsch ${ }^{4}$ \\ DLR, 37073 Göttingen, Germany
}

\begin{abstract}
The Aircraft Noise Simulation Working Group (ANSWr), comprised of NASA, DLR, and ONERA, recently completed an analysis campaign to compare aircraft noise simulation tools, establish guidelines for noise prediction, and launch activities to assess uncertainties associated with the simulation. The campaign included the analyses of two DLR conceptual aircraft, a reference tube-and-wing aircraft, and a low noise aircraft with engines mounted above the fuselage-wing-junction. While the total predicted noise for each of the concepts compared favorably among analyses at the peak level, significant differences were noted at the component level. This paper aims to further that effort by auralizing aircraft flyover noise associated with those predictions. Comparisons are made among the NASA, DLR/Empa, and ONERA generated sounds to determine how differences between the system noise prediction and auralization methods result in changes to the auralized sound.
\end{abstract}

\section{Introduction}

$\mathrm{R}$ ECENT work conducted under the auspices of the Aircraft Noise Simulation Working Group (ANSWr) compared system noise predictions of reference and low noise concept aircraft. ${ }^{1,2}$ In particular, the National Aeronautics and Space Administration (NASA), the German Aerospace Center (Deutsches Zentrum für Luft- und Raumfahrt, DLR), and the French Aerospace Lab (Office National d'Etudes et de Recherches Aérospatiales, ONERA) each performed system noise simulations using their own tools, based on identical input data provided by DLR, in an effort to establish guidelines for noise prediction, and to assess uncertainties associated with the simulations. The work demonstrated that while peak levels of the total noise agreed favorably, significant differences among analyses were observed at the component level (notably in the airframe noise components and level of fan tones), and in the shielding calculation of the low noise concept. This paper aims to build upon that work to determine how those differences affect the auralized sounds, which in this context means the simulated sound at the receiver.

Auralization is a technique for creating audible sound files from numerical data, ${ }^{3}$ in this case from the system noise predictions. Auralization of air vehicle noise can serve several purposes: it provides a means of communicating noise impact to stakeholders in a natural form; it provides feedback to the noise analyst regarding the system under design; and it serves as an integral element of perception-influenced design of new air vehicles. ${ }^{4}$ It is with regard to the second and third purposes that the present study is most applicable.

This paper first summarizes the recent comparison of system noise predictions for reference and low noise aircraft concepts. Auralizations based on each of the system noise predictions, using tools from NASA, the Swiss

\footnotetext{
${ }^{1}$ Senior Researcher for Aeroacoustics, Aeroacoustics Branch, AIAA Fellow

${ }^{2}$ DAAA, Aerodynamics, Aeroelasticity, and Acoustics Department

${ }^{3}$ Head of the Environmental Acoustics group, Laboratory for Acoustics / Noise Control

${ }^{4}$ Institute of Aerodynamics and Flow Technology, AIAA Member
} 
research institute Empa, and ONERA, then follow. As such, the auralizations reflect combined differences in the system noise predictions and in the auralization tools themselves. The auralizations are then compared qualitatively and quantitatively to understand how differences in the system noise prediction and auralization methods result in changes to the auralized sound. It is intended that the auralizations will serve as test stimuli in a future psychoacoustic test to better understand how well various sound metrics reflect human response.

\section{Aircraft Descriptions}

The aircraft models were selected from a 2013 DLR low noise design study. ${ }^{5}$ The models are based on an Airbus A319 and were generated with the aircraft design synthesis code, Preliminary Aircraft Design and Optimization (PrADO), of TU Braunschweig. ${ }^{6}$ PrADO is comprised of dedicated simulation modules that each are assigned to a specific task in the aircraft design process, e.g., mass estimation or wing aerodynamics. The PrADO simulation process can generate all input data that are required for a system noise prediction, e.g., flight trajectories with detailed information on configuration and operation of the aircraft during departure and approach. ${ }^{5}$ To enable an automated low noise aircraft design process, the DLR software, Parametric Aircraft Noise Analysis Module (PANAM), was directly integrated as a simulation module within PrADO. The overall low noise design process was then applied to identify promising low noise tube-and-wing aircraft concepts. The low noise design study focused on the reduction of engine fan noise, a significant source during departure and a relevant noise source during approach. The selected measure to achieve this reduction is engine noise shielding by the airframe structure, i.e., no other low noise technologies are considered. For the vehicle design study, the module for engine design and performance calculation within PrADO was replaced by available high quality engine data from DLR. ${ }^{7}$ Design details, e.g., rotor-stator-spacing, and the resulting performance map of the overall engine come from high-fidelity DLR simulations and replace the inherent engine simulation module of PrADO. Within the underlying low noise design study, this reference engine is similar to a CFM-56 and was furthermore kept constant and no alternative engine concepts are assessed here.

Selected key aircraft design parameters have been modified to identify promising low noise aircraft architectures, e.g., wing shape and engine installation location. The analysis of each vehicle variant included a full simulation and convergence of the aircraft and engine main design parameters. Each variant was simulated along a defined design mission and along individual approach and departure trajectories to predict performance and system noise. Modifications to main aircraft and engine design parameters directly influence the aircraft flight performance, and hence will result in different flight trajectories, i.e., velocity, thrust, and configurational setting along a prescribed flight procedure.

The resulting most promising low noise architecture, a high-wing vehicle with engine installation above the fuselage-wing-junction, is referred to as $\mathrm{V}-2$ and furthermore investigated and compared to the reference aircraft V-R. ${ }^{1,2}$ Figure 1 shows the reference (V-R) aircraft and the low noise concept (V-2) exploiting shielding.

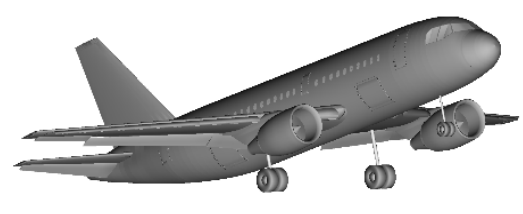

(a) Reference vehicle V-R.

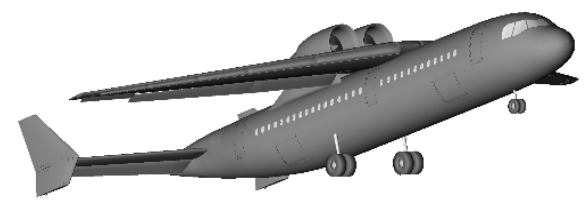

(b) Low noise vehicle with shielding V-2.

Figure 1: DLR designed aircraft ${ }^{5}$ considered in this study.

\section{System Noise Predictions}

NASA, DLR, and ONERA each performed system noise predictions of the V-R ${ }^{1}$ and $\mathrm{V}-2^{2}$ aircraft. Great effort was made to ensure that the input data for each system noise prediction tool were, as much as possible, identical among the organizations, and consistent with the data from the low noise design study. ${ }^{5}$ The NASA predictions were performed using the Aircraft Noise Prediction Program 2 (ANOPP2), ${ }^{8}$ of which ANOPP ${ }^{9}$ is a component. The DLR predictions were performed using the Parametric Aircraft Noise Analysis Module (PANAM). ${ }^{5}$ The ONERA predictions were performed using the tool, Codes Acoustiques par Rayons pour la Modélisation et l'Estimation de Nuisances (CARMEN), ${ }^{10}$ a component of the Infrastructure d'Evaluation de Systèmes de Transport Aérien (Infrastructure for Evaluating Air Transport Systems, IESTA) ${ }^{11}$ tool. Each is very briefly summarized below, and results of the system noise analyses are provided. 


\section{A. ANOPP2}

NASA has been continually developing an aircraft system noise prediction capability since the 1970 s beginning with ANOPP. ${ }^{9}$ For more than ten years, both the noise prediction methods of ANOPP and the second generation framework, ANOPP $2,{ }^{8}$ continue to be developed specifically for the challenges of higher fidelity predictions and the need for expanded capability to accurately predict future, advanced low noise aircraft configurations ${ }^{12}$ for which propulsion airframe aeroacoustic effects are critical.

The same prediction methods are applied here to compute the system noise of the V-R and V-2 aircraft using ANOPP2. However, for the V-2 aircraft, an additional prediction method is required to estimate the shielding of the engine sources by the airframe. NASA's method for scattering prediction follows the general approach for high frequency acoustics. Since 2017, the NASA team has completely reformulated and recoded the Guo et al. method in a new research scattering code named Propulsion Airframe Aeroacoustic Scattering for System Noise (PAASSyN) ${ }^{13-15}$ The NASA prediction of noise shielding for the V-2 aircraft was performed with an early version of the PAASSyN code without the effect of mean flow.

\section{B. PANAM}

DLR activities in the field of noise source modeling can be found in the literature starting around 2000. ${ }^{16-18}$ Since then, noise source models for additional sources continue to be introduced, while older models have been developed further. Thereby, the noise source models can be fully empirical (simple data fit), semiempirical, or analytical. Work has also been done to include and account for interaction effects. Beginning in 2008, the DLR noise source models have been implemented into an aircraft system noise simulation process. ${ }^{5}$ Since then, the corresponding simulation tool PANAM has been further improved and updated, e.g., to incorporate noise shielding effects and acoustic lining material.

The analysis of propulsion airframe aeroacoustic interaction effects is essential when investigating low noise aircraft concepts such as the V-2. ${ }^{19}$ Consequently, at DLR, multiple simulation tools of varying fidelity are available. A ray tracing tool called SHADOW was specifically developed in order to investigate different engine installations with respect to noise shielding at low computational costs. ${ }^{20}$ The SHADOW version used to predict the shielding effects for the V-2 aircraft did not account for effects of mean flow.

\section{CARMEN}

For about 10 years, the system noise prediction tool CARMEN ${ }^{10}$ has been developed at ONERA within the IESTA $^{11}$ tool - a platform dedicated to environmental impact, in terms of noise and chemical emissions, of the air traffic surrounding airports. CARMEN is composed of three modules: the acoustic source module, the installation effects module, and the atmospheric propagation module. Each of these modules is assessed against reference results from experiments, analytical solutions, or simulations. Most of the noise source models are based on semiempirical models derived from the literature. Prior to their implementation in CARMEN, these models had been assessed against experimental results obtained by ONERA. ${ }^{10}$

The module for installation effects is based on either a ray model, which accounts for direct and reflected rays, as well as the diffraction by the whole aircraft geometry, or the boundary element method (BEM), which computes the acoustic field diffracted by the whole aircraft geometry. In the present simulation, the diffraction effect of the aircraft geometry was computed using BEM and the effect of mean flow was not taken into account. The atmospheric propagation module, also based on the ray model, includes the effects of wind, temperature gradients, and atmospheric absorption along the ray path.

\section{System Noise Prediction Results}

The system noise predictions undertaken herein are based on simulation cases \#5-8 from the earlier studies. ${ }^{1,2}$ To first recap, for each aircraft, two simplified flight trajectories were considered: i) a constant operating condition approach with a $3.4^{\circ}$ glide slope, having an altitude of $428.7 \mathrm{~m}$ at the centerline observer location, and ii) a constant operating condition departure with a $6.7^{\circ} \mathrm{climb}$ angle, having an altitude of $613.8 \mathrm{~m}$ at the centerline observer location. As a modification from the earlier studies, observers were located $1.2 \mathrm{~m}$ above grass covered ground having a flow resistivity of $250,000 \mathrm{~kg} /\left(\mathrm{s}-\mathrm{m}^{3}\right)$. There was no ground attenuation in the earlier studies; free-field conditions were assumed. An observer along the centerline was considered for all approach and departure cases, and a sideline observer located a lateral distance of $910 \mathrm{~m}$ was also considered for the V-2 departure case. In contrast to the lapse atmosphere in the earlier studies, a uniform atmosphere at $1 \mathrm{~atm}$ pressure, $15^{\circ} \mathrm{C}$ temperature, $1.225 \mathrm{~kg} / \mathrm{m}^{3}$ density, and $70 \%$ relative humidity, was considered to facilitate the auralization comparisons. A summary of flight conditions is provided in Table 1 (cases \#5-6 described in Bertsch et al., ${ }^{1}$ cases \#7-8a described in Sanders et al. ${ }^{2}$ ). 
Table 1: Summary of flight conditions.

\begin{tabular}{ccccccc} 
Case \# & Aircraft & Condition & Observer Location & Shielding & Engine Lining & Ground Surface \\
\hline \hline 5 & V-R & Approach & Centerline & No & No & Grass \\
6 & V-R & Departure & Centerline & No & No & Grass \\
7 & V-2 & Approach & Centerline & Yes & No & Grass \\
8 & V-2 & Departure & Centerline & Yes & No & Grass \\
$8 \mathrm{a}$ & V-2 & Departure & Sideline & Yes & No & Grass
\end{tabular}

Broadband airframe noise sources included trailing edge, flap side edge, leading edge, and main and nose landing gear noise. Engine broadband noise sources included fan broadband and jet noise. Engine tonal sources included fan rotor-stator interaction tones and combination tones, also referred to as multiple pure tone (MPT) or buzzsaw noise. A summary of source noise models used in each of the three system noise predictions is provided in Table 1 of Bertsch et al. ${ }^{1}$ Models used for the atmospheric absorption and ground plane reflection (not included in the prior works) are provided in Table 2. Note that the ANSI S1.26-2014 absorption model is the United States equivalent of ISO 9613-1.

Table 2: Summary of sound propagation models used.

\begin{tabular}{cccc} 
Propagation Effect & ANOPP2 & PANAM & CARMEN \\
\hline \hline Atmospheric Absorption & ANSI S1.26-2014 & ISO 9613-1 & ISO 9613-1 \\
\hline Reflection Model & Chien-Soroka $^{22}$ & & SAE AIR1751 \\
\cline { 1 - 1 } \cline { 4 - 4 } Ground Impedance & Delany-Bazley $^{25}$ & & Plane wave \\
\hline
\end{tabular}

Finally, DLR updated its PANAM shielding maps since the earlier study on the V-2. ${ }^{2}$ Distributed fan source locations along the fan diameter are now considered. The updated maps, shown for $1 \mathrm{kHz}$ in the center column of Figure 2 as a function of polar, $\theta$, and azimuthal, $\phi$, emission angles, were used by PANAM in the present study. The existing shielding maps used in NASA's ANOPP2 and ONERA's CARMEN codes are unchanged from the previous study but are shown for completeness.

\section{Integrated Certification Metrics}

Although the flight operations considered herein were not simulated in accordance with ICAO Annex $16^{26}$ noise certification procedures, the applicable metric, effective perceived noise level (EPNL), remains a useful one for comparing prediction results, as it takes into account both level and duration. EPNL values were computed independently by NASA, DLR, and ONERA, for each of their respective predictions, and are provided in Table 3. Although the comparisons in the earlier works ${ }^{1,2}$ were made on the basis of the A-weighted sound pressure level $\left(L_{A}\right)$ and, more specifically, differences in the maximum levels $\left(L_{A \max }\right)$, the maximum difference in EPNL of $3.2 \mathrm{~dB}$ is within the range of previously reported differences in $L_{A \max }$ of 3-4 dB.

\section{Certification Metric Time Histories}

Greater insight into the differences in EPNL among methods can be gained by examining the tone-corrected perceived noise level (PNLT) time histories, shown in Figure 3 - Figure 8. Recall that EPNL is the integration of PNLT between the $10 \mathrm{~dB}$ down times on either side of PNLT $\mathrm{T}_{\max }$. Note that in each of these and subsequent time history plots, the traces were aligned to a common receiver time at which the aircraft was in the overhead position. Small variances $( \pm 0.5 \mathrm{~s})$ may result due to the interval at which metrics are calculated. The shape of the PNLT traces for the V-R aircraft in Figure 3 and Figure 4 resemble the $L_{A}$ traces in Figure 8a/b in Bertsch et al. ${ }^{1}$ The jaggedness of the CARMEN traces is attributable to the approximate manner in which the ground plane reflection was simulated. For the approach condition (\#5), the higher value of EPNL from the CARMEN prediction is attributed to greater magnitude and duration relative to the ANOPP2 and PANAM predictions. 


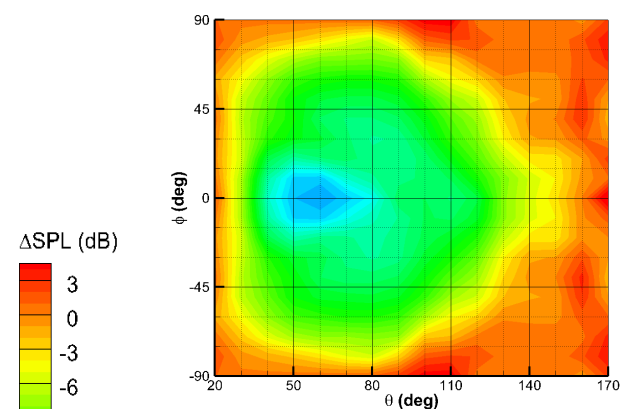

ANOPP2 (inlet)

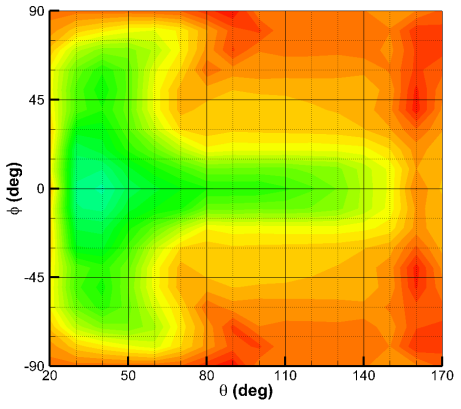

ANOPP2 (aft)

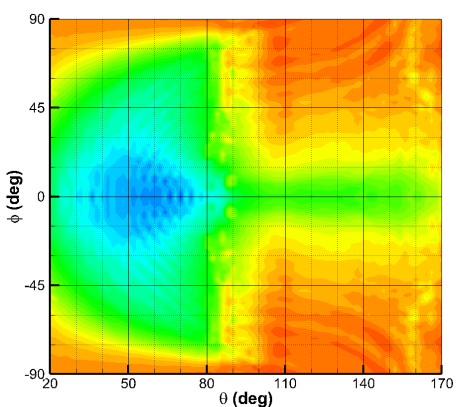

PANAM (inlet)

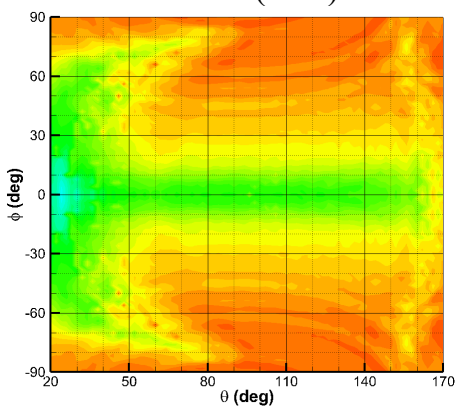

PANAM (aft)

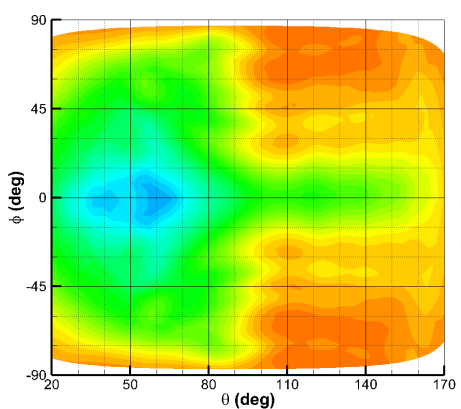

CARMEN (inlet)

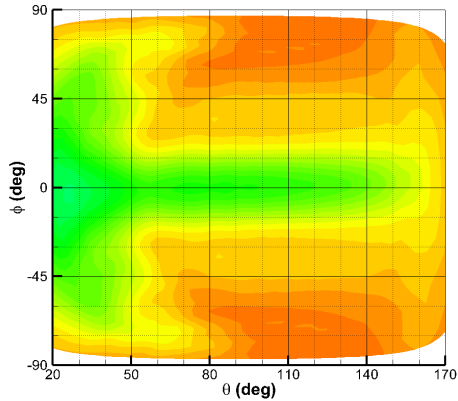

CARMEN (aft)

Figure 2: V-2 shielding maps predicted by shielding tools for engine noise sources emitted at $1 \mathrm{kHz}$ (inlet maps applied to forward radiating fan noise components, aft maps applied to aft radiating fan and jet noise components).

The shape of the PNLT traces for the V-2 aircraft in Figure 5 - Figure 8 likewise resemble those of the total noise in Figure 9 and Figure 11 in Sanders et al. ${ }^{2}$ Differences in the PNLT time histories are generally greater for the V-2 aircraft, and these are largely attributable to differences in shielding. For the approach condition (\#7), the CARMEN EPNL value is about $2 \mathrm{~dB}$ higher than either the ANOPP2 or PANAM values; however, the PNLT traces in Figure 5 visually indicate better agreement between the ANOPP2 and CARMEN predictions. The greater EPNL from the ANOPP2 prediction of departure condition (\#8) is clearly attributable to its greater duration, see Figure 6. It is difficult to directly use the shielding data in Figure 2 to draw conclusions on specific differences because the data shown are only at a single frequency, and that frequency does not necessarily coincide with the spectral peak of the dominant noise sources.

Table 3: Comparison of EPNL(dB) from three system noise prediction methods for each flight operation

\begin{tabular}{cccc}
$\begin{array}{c}\text { Operation } \\
\text { / Case \# }\end{array}$ & ANOPP2 & PANAM & CARMEN \\
\hline \hline $\begin{array}{c}\text { V-R app. } \\
/ 5\end{array}$ & 85.4 & 85.0 & 88.2 \\
\hline $\begin{array}{c}\text { V-R dep. } \\
/ 6\end{array}$ & 91.6 & 92.7 & 91.5 \\
\hline $\begin{array}{c}\text { V-2 app. } \\
/ 7\end{array}$ & 78.7 & 78.8 & 80.8 \\
\hline $\begin{array}{c}\text { V-2 dep. } \\
/ 8\end{array}$ & 80.8 & 79.5 & 78.2 \\
\hline $\begin{array}{c}\text { V-2 dep. } \\
\text { / 8a }\end{array}$ & 82.0 & 82.4 & 82.6 \\
\hline
\end{tabular}

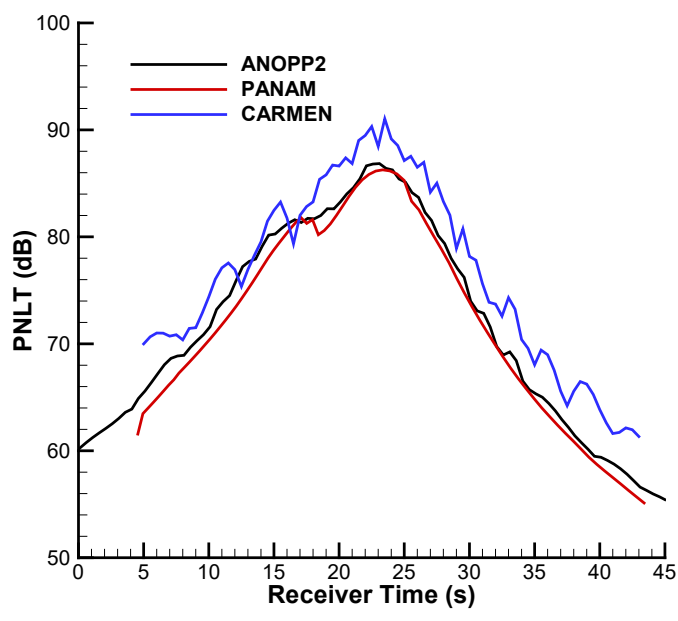

Figure 3: Comparison of PNLT predictions for V-R aircraft on approach (\#5). 


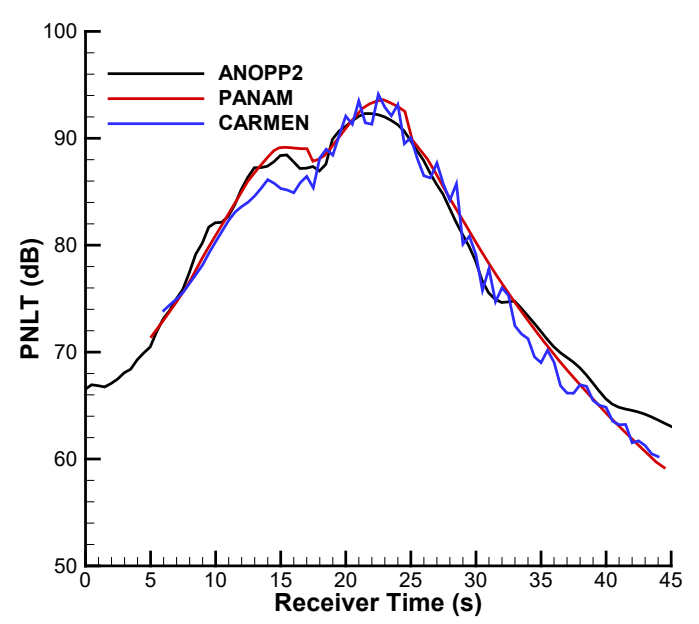

Figure 4: Comparison of PNLT predictions for V-R aircraft on departure (\#6).

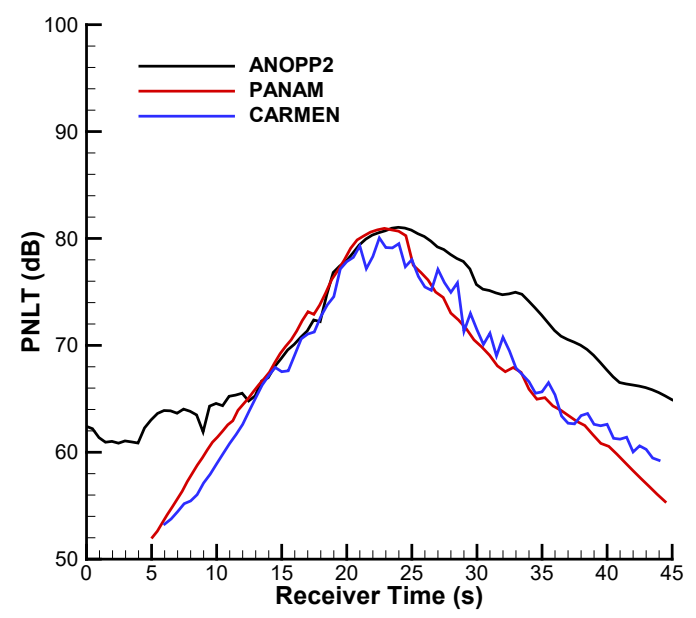

Figure 6: Comparison of PNLT predictions for V-2 aircraft on departure (\#8, centerline obs.).

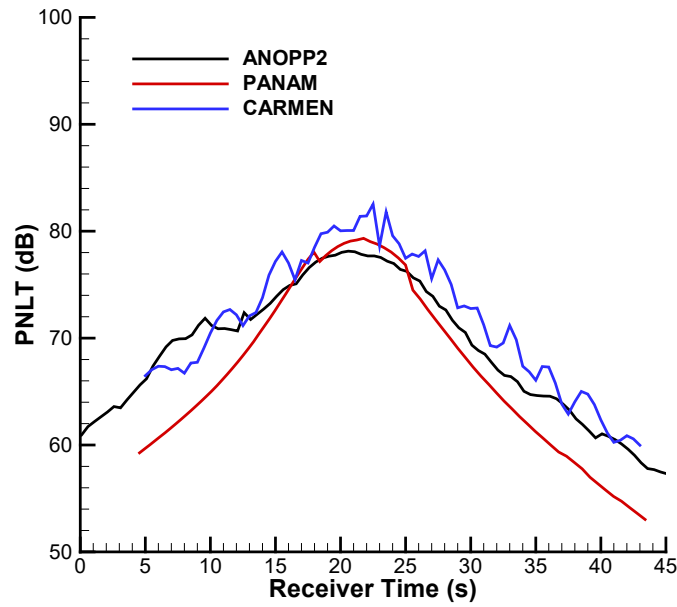

Figure 5: Comparison of PNLT predictions for V-2 aircraft on approach (\#7).

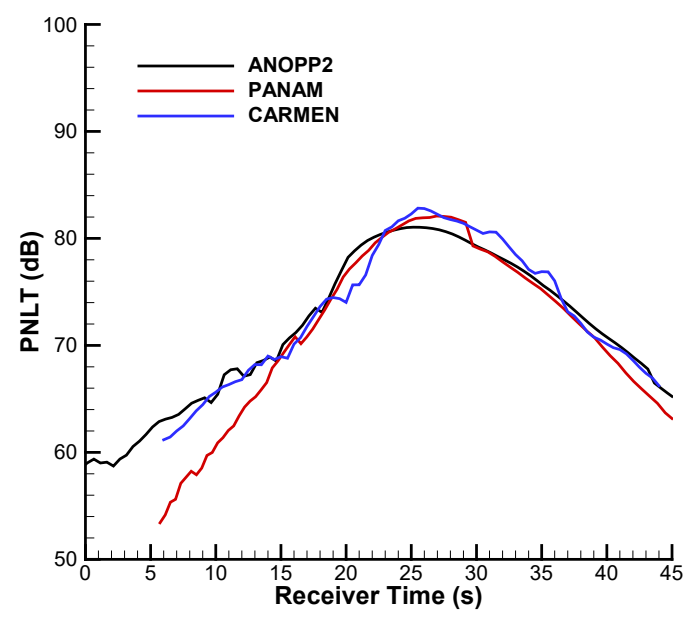

Figure 7: Comparison of PNLT predictions for V-2 aircraft on departure (\#8a, sideline obs.).

\section{Auralization}

There are several elements of auralization that are common to any purpose or environment. Following a sourcepath-receiver paradigm, these elements include sound synthesis, sound propagation, and receiver simulation. Synthesis is the process by which a pressure time history is generated. Propagation conveys the sound from the source to the observer. The synthesis operation may either precede or be subsequent to the propagation operation. If sound synthesis precedes propagation, synthesis is performed at the source and propagation is performed in the time domain. If sound synthesis is subsequent to propagation, propagation is performed in the frequency domain and synthesis is performed at the receiver. Finally, the sound may be additionally prepared for reproduction to a listener in a monaural, binaural or multichannel sense. A simple flowchart depicting the above processes is shown in Figure 8.

In this work, the source definitions (one for each noise component, e.g., jet) are provided by ANOPP2, PANAM, or CARMEN, and are based on predefined and identical input data. The result of the auralization is a monaural signal at the receiver that is referred to as a pseudorecording. The pseudorecording is generated in engineering units, e.g., $\mathrm{Pa}$, and can be further analyzed for generation of metrics, etc. Auralizations by NASA and Empa follow the time domain approach, while auralizations by ONERA follow the frequency domain approach. In a sense, the system noise predictions follow the frequency domain approach, but without receiver noise synthesis. Metrics 
generated from auralizations made using the time domain approach should be comparable to those from the system noise prediction as long as equivalent propagation models in the time domain are used. A more detailed comparison of time and frequency domain approaches is provided by Rizzi and Sahai. ${ }^{27}$ A brief summary of the auralization tools used by NASA, DLR/Empa, and ONERA is presented next.

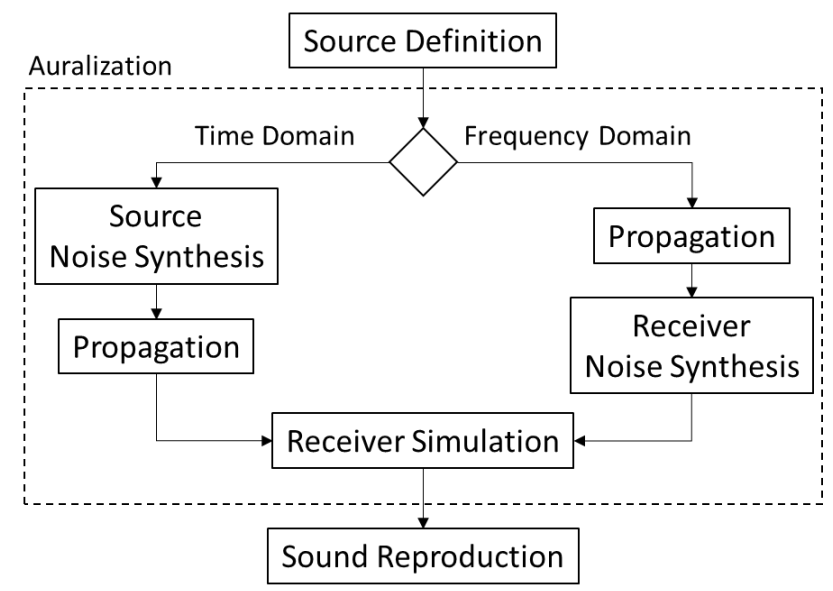

Figure 8: Flowchart depicting the auralization process in the time and frequency domains.

\section{A. NAF}

The NASA Auralization Framework (NAF) and the NAF advanced plugin libraries ${ }^{28}$ offer the means to auralize system noise predictions of aircraft flyovers according to the methods described by Rizzi and Sahai. ${ }^{27}$ The ANOPP2-NAF interface library ${ }^{29}$ allows source definitions from the system noise prediction (stored in ANOPP2 observer restart files) to be read by a NAF user code. A method ${ }^{30}$ for synthesizing buzzsaw noise was developed and implemented in the predecessor synthesis code ASoNG. ${ }^{31}$ The method was implemented as a NAF synthesis type during the course of this study.

The time-marching approach of the NAF synthesizes the individual noise components at the time of emission based on the straight-line paths (one for the direct ray and one for the ground-reflected ray) between the source and observer. Different synthesis methods are used for broadband and tonal noise components. ${ }^{27}$ Propagation to the receiver is performed through application of a distance-dependent, negative gain (for geometrical spreading), a timevarying delay line (simulating Doppler frequency shift), and finite impulse response (FIR) filters for atmospheric absorption and ground reflection. Convective amplification is included in the ANOPP2 source definition. The absorption filter is based on the ANSI S1.26-2014 ${ }^{21}$ model, and ground attenuation on the one-parameter Delany and Bazley ground impedance mode ${ }^{25}$ with a plane wave reflection model. Only the plane wave reflection model differs from the ANOPP2 propagation using the Chien-Soroka model, ${ }^{23}$ which applies a spherical correction for propagation that is near-parallel with the ground. That correction is largely not applicable for the cases studied.

\section{B. AURAFONE}

For more than a decade, the Swiss research institute Empa has advanced scientific progress in environmental sound auralization and has developed sound synthesis models for wind turbines,${ }^{32}$ road, ${ }^{33}$ rail,${ }^{34}$ and air vehicles. For the auralization of jet aircraft, Empa developed the software AURAFONE (AURalization of Aircraft FlyOver Noise by Empa) that synthesizes sounds of virtual jet aircraft flybys as perceived outdoors. ${ }^{35,36}$ Input data describing the sources can be read directly from PANAM. ${ }^{35}$

Because AURAFONE uses a time domain auralization approach, it operates in fundamentally the same manner as the NAF, and uses similar synthesis and propagation techniques. Source signals for the different aircraft noise sources are artificially created using parametric signal-based synthesis techniques. Like the NAF, airframe and engine broadband noise are generated using a subtractive synthesis method, and engine fan tonal and buzzsaw noise are created using an additive synthesis method. Propagation simulation includes geometrical spreading, Doppler frequency shift, atmospheric absorption, and ground reflection. Doppler frequency shift is implemented by bandlimited windowed sinc interpolation. ${ }^{33}$ The frequency-dependent absorption coefficients to simulate air absorption are computed using ISO 9613-1. ${ }^{22}$ The ground plane reflection is simulated by interference of direct sound and reflected sound of a spherical wave ${ }^{23}$ at an infinite complex-valued impedance plane. The ground impedance is predicted using the one-parameter model from Delany and Bazley. ${ }^{25}$ The ground reflection and 
impedance models differ from the semiempirical SAE AIR1751 lateral attenuation mode ${ }^{24}$ used in the PANAM system noise prediction.

\section{FLAURA}

Auralization of CARMEN system noise predictions was performed using the recently developed FLAURA code. The FLAURA tool makes it possible to create audible sounds from numerical data, in this case, output from CARMEN. In contrast to the NAF and AURAFONE codes, FLAURAv0 adopts a frequency domain auralization approach. Specifically, it uses the free-field spectra at the receiver position, calculated by CARMEN at discrete time steps, as input. Propagation effects, including atmospheric absorption, ${ }^{22}$ spreading loss, and Doppler shift, are therefore already incorporated by CARMEN.

The ground plane reflection is simulated through application of a corrective factor that is applied to the reflected ray. The corrective factor is based on the Delany and Bazley ${ }^{25}$ impedance model with a plane wave reflection model. FLAURAv0 separately treats broadband and tonal noise components. Like the NAF and AURAFONE, broadband synthesis is performed using the overlap-add method ${ }^{37}$ to avoid discontinuities in the generated signal. For the tonal components, a multitone synthesis is performed. ${ }^{38}$ The pseudorecording is generated in the time domain as the sum of the resulting broadband and tonal noise signatures.

A second version, FLAURAv1, using a time domain auralization approach, is currently under development. The goal is to convert the simulated source noise spectra into the time domain directly at the source. All propagation effects, including atmospheric absorption, spreading loss, Doppler shift, and ground plane reflection, are then simulated fully in the time domain, like the NAF and AURAFONE codes.

\section{Auralization Results}

\section{Integrated Certification Metrics}

Pseudorecordings from the NAF, AURAFONE, and FLAURA codes for each case are available for download ${ }^{39}$ as 32-bit floating point PCM WAV files in units of Pa. All were post-processed using the ANOPP2 Acoustic Analysis Utility to generate EPNL and PNLT metrics. The EPNL values from the three auralization methods, along with differences relative to their respective system noise predictions, are provided for each flight condition in Table 4. Like the system noise predictions themselves, the EPNL values among auralization methods compare very favorably. As expected, the V-R pseudorecordings are noticeably louder than the V-2 auralizations, for the respective operations, upon auditioning. Note that because auralization of turbofan aircraft noise sources uses random noise for broadband synthesis and random phase for tonal synthesis, EPNL values may differ by a few tenths of a dB between realizations. Those differences are not audible for this class of aircraft, and no attempt was made to select the 'best' auralization in this work. Differences between the auralizations and their respective system noise predictions are typical of such comparisons and provide a measure of consistency between the two methods. The EPNL metric, however, offers no explanation for the differences. For that, additional information is required.

\section{Certification Metric Time Histories}

Examination of the PNLT traces, shown in Figure 9 - Figure 13, offers some reasons for the EPNL differences noted between auralizations and system noise predictions. To facilitate comparisons, the AURAFONE/PANAM and FLAURA/CARMEN results are shifted up by 20 and $40 \mathrm{~dB}$, respectively. Consider the comparison of NAF and ANOPP2 traces. There is generally very good agreement across the duration of the approach condition flyovers $(\# 5,7)$. While mostly true for the departure flyovers $(\# 6,8,8 \mathrm{a})$, greater differences are observed for receiver times less than about $10 \mathrm{~s}$. It might be tempting to attribute these differences to the ground reflection model, i.e., the plane wave reflection model used by the NAF vs. the spherical wave reflection model used by ANOPP2. However, inspection of the tone penalty used in the PNLT calculation indicates a maximal value of $6.7 \mathrm{~dB}$ (attributable to the $4 \mathrm{kHz} 1 / 3$-octave band) in the NAF results (not shown), and a tone penalty of less than $2.6 \mathrm{~dB}$ (attributable to the $2 \mathrm{kHz}$ and $2.5 \mathrm{kHz} 1 / 3$-octave bands) in the ANOPP2 results. The reason for that will be apparent in the spectrograms shown in Section IV.D.3, and tone-to-noise ratio shown in Section IV.D.4.

Differences between the AURAFONE auralization metrics and those from the PANAM predictions are most likely associated with the different propagation models used. Both tools start with the identical noise source description, but then apply different models to simulate propagation to a ground observer. Because of that, an equivalency of metrics results following propagation is not expected. The SAE AIR1751 model used by PANAM in this study accounts for the combined effects of ground, meteorological, and engine installation. The fact that it includes installation effects, albeit for older generation fuselage-mounted engines, adds to the shielding already provided by the SHADOW tool. The more recent SAE AIR5662 model ${ }^{40}$ separates the contributions from ground and refraction-scattering attenuation, and different engine installations. Attenuation in SAE AIR1715 is a function 
of distance (increasing attenuation with increasing distance), and elevation angle (increasing attenuation with decreasing angle). The dependency on distance and elevation angle is especially apparent on the approach cases $(\# 5,7)$, but is less so for the departure cases $(\# 6,8,8 \mathrm{a})$.

Table 4: Comparison of EPNL (dB) from three auralizations and differences [ ] relative to system noise predictions for each flight operation.

Operation

\begin{tabular}{cccc} 
/ Case \# & NAF & AURAFONE & FLAURA \\
\hline \hline V-R app. & 85.6 & 85.6 & 86.7 \\
$/ 5$ & {$[-0.2]$} & {$[-0.6]$} & {$[1.5]$} \\
\hline V-R dep. & 91.5 & 91.4 & 92.4 \\
$/ 6$ & {$[0.1]$} & {$[1.3]$} & {$[-1.0]$} \\
\hline V-2 app. & 79.2 & 81.4 & 79.5 \\
$/ 7$ & {$[-0.5]$} & {$[-2.6]$} & {$[1.3]$} \\
\hline V-2 dep. & 80.5 & 78.4 & 79.0 \\
/ 8 & {$[0.3]$} & {$[1.1]$} & {$[-0.8]$} \\
\hline V-2 dep. & 81.2 & 81.6 & 83.3 \\
/ 8a & {$[0.9]$} & {$[0.8]$} & {$[-0.7]$} \\
\hline
\end{tabular}

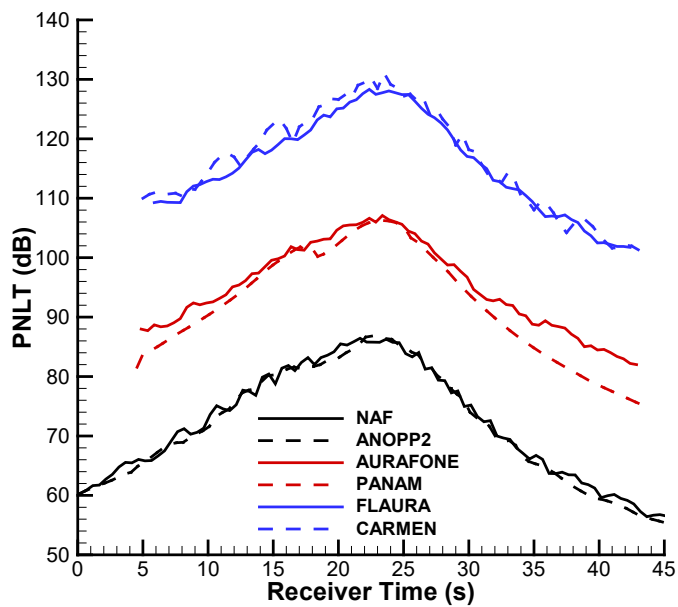

Figure 9: Comparison of PNLT auralizations for V-R aircraft on approach (\#5).

Comparison of FLAURA and CARMEN metrics are very favorable across the departure cases $(\# 6,8,8 \mathrm{a})$, with small differences noted on the approaching side of the approach cases $(\# 5,7)$. The favorable agreement is expected given that the synthesis follows propagation simulation in the frequency domain auralization approach used.

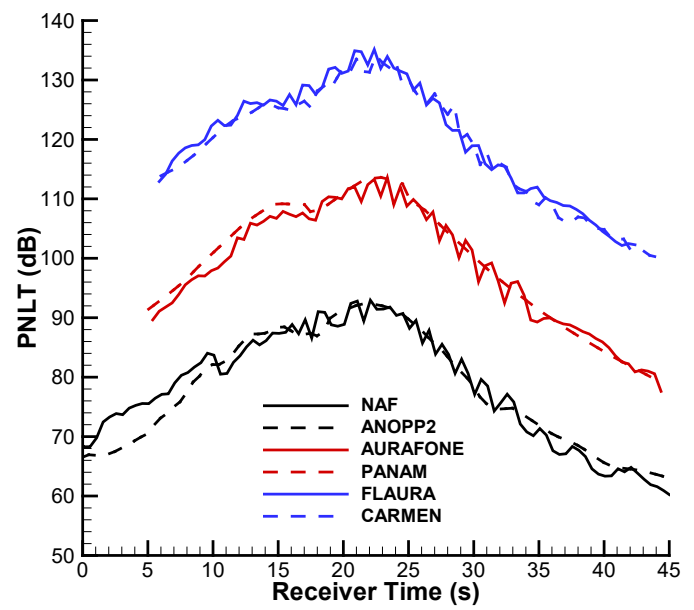

Figure 10: Comparison of PNLT auralizations for V-R aircraft on departure (\#6).

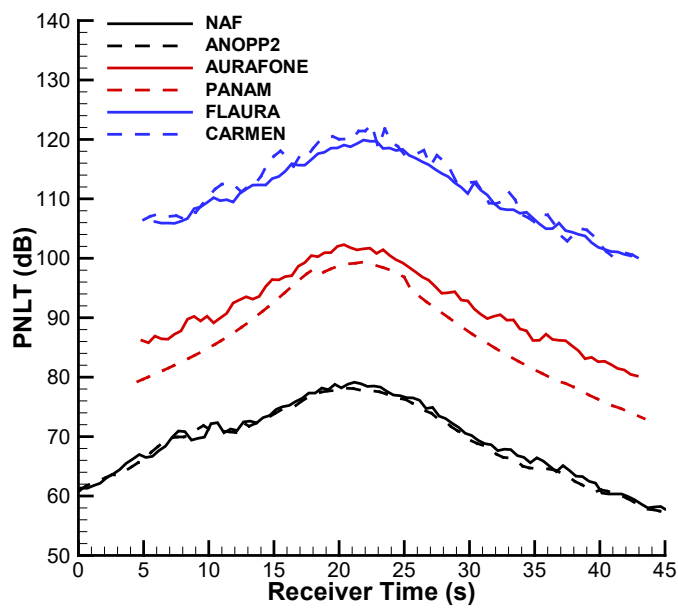

Figure 11: Comparison of PNLT auralizations for V-2 aircraft on approach (\#7).

Finally, irrespective of the favorability of the comparisons between auralizations and their respective system noise predictions, it is expected that differences among the NAF, AURAFONE, and FLAUA auralizations will have more to do with differences in the source definition than with the small differences among the propagation models used. 


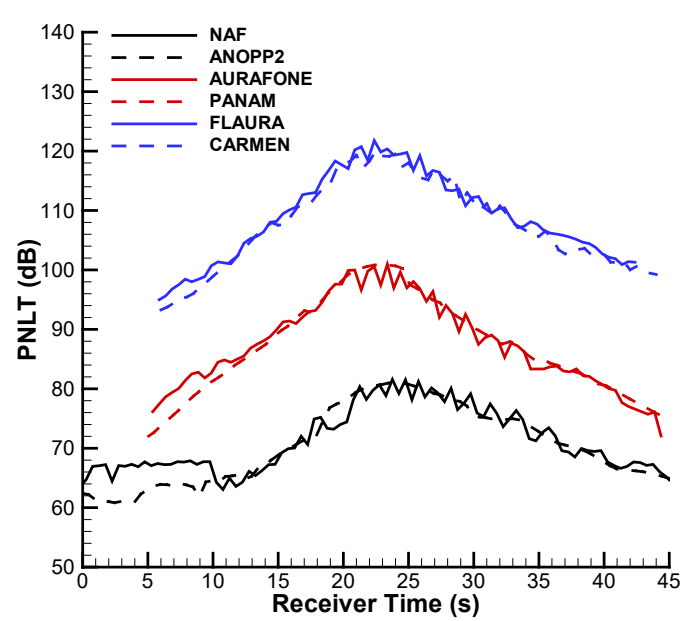

Figure 12: Comparison of PNLT auralizations for V-2 aircraft on departure (\#8, centerline obs.).

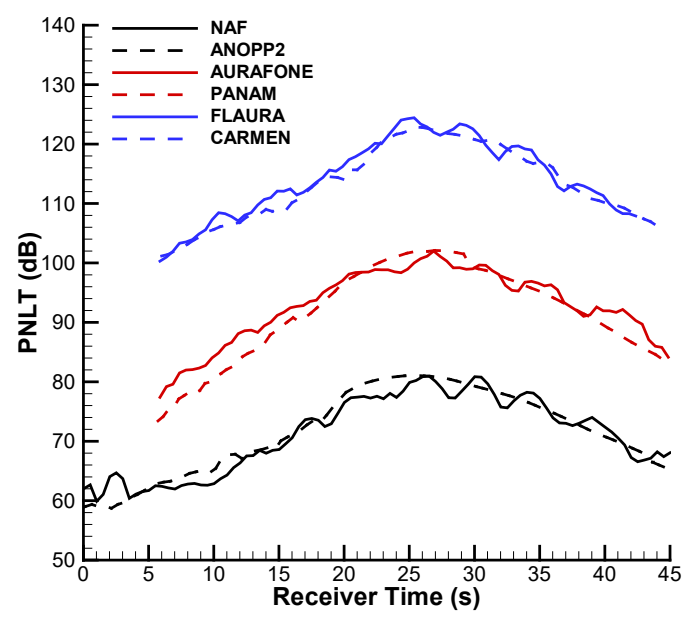

Figure 13: Comparison of PNLT auralizations for V-2 aircraft on departure (\#8a, sideline obs.).

\section{Spectrograms}

Additional information about the auralizations can be ascertained through examination of the spectrograms, shown in Figure 14 - Figure 19. The spectrograms were calculated from the pseudorecordings. An immediate characteristic observed across all conditions are differences in the spectral balance among the various methods. In each case, the AURAFONE spectrograms show the least high frequency content, followed by the NAF and the FLAURA spectrograms, respectively. What is seen in the spectrograms can also be heard when auditioning the pseudorecordings. Spectral differences may be more attributable to differences in the source noise descriptions themselves, rather than those arising from differences among propagation models that are intended to be nearly identical across all three auralization methods. Further, significant differences of up to $6 \mathrm{~dB}$ were noted in individual airframe noise components, particularly at high frequencies, in the earlier studies. ${ }^{1,2}$ It is important to note, however, that the high frequency differences noted are more than $30 \mathrm{~dB}$ lower than the maximum (low frequency) values.

The next most striking feature in the spectrograms is the frequency banding seen in the FLAURA and, to a lesser extent, the NAF spectrograms. This is a result of synthesis and propagation implementations. In the FLAURAv0 code, the atmospheric absorption is applied on a 1/3-octave band basis, and the spectrum at the receiver is synthesized uniformly within each $1 / 3$-octave band. In the NAF, the spectrum at the source is synthesized uniformly within each 1/3-octave band, but absorption is applied on a narrowband basis. In the AURAFONE, the spectrum at the source is distributed nonuniformly within each 1/3-octave band and the absorption is applied on a narrowband basis. In this frequency range, the banding is not noticeable during auditioning.

Focusing next on differences between flight operations, consistent with the EPNL values in Table 4, the levels are visually higher for the V-R aircraft than for the V-2 aircraft. The effect of shielding is seen in the V-2 aircraft spectrograms, more so for the departure cases (Figure 17 and Figure 18) than the approach case (Figure 16), and more prominently in the FLAURA and NAF spectrograms than in the AURAFONE spectrogram.

Rotor-stator interaction tones at the blade passage frequency (BPF) and its harmonics are prominent in all spectrograms of the V-R aircraft on both approach (1452 Hz BPF) and departure (2776 Hz BPF). Rotor-stator interaction tones for the V-2 aircraft are at the same BPFs as the V-R aircraft under approach and departure conditions, but are significantly reduced due to shielding. From the departure spectrograms, it is apparent why the NAF PNLT tone penalties were found to be high for receiver times less than $10 \mathrm{~s}$.

Buzzsaw noise is more visible on a magnified frequency scale. Examples are provided in Figure 19 for the V-R aircraft on departure. Tones are visible at Doppler-shifted harmonics of the shaft order frequency at $77 \mathrm{~Hz}$. Small differences in the interference patterns between direct and ground reflected rays indicate that the ground impedance models are close but not identical among auralization methods. 


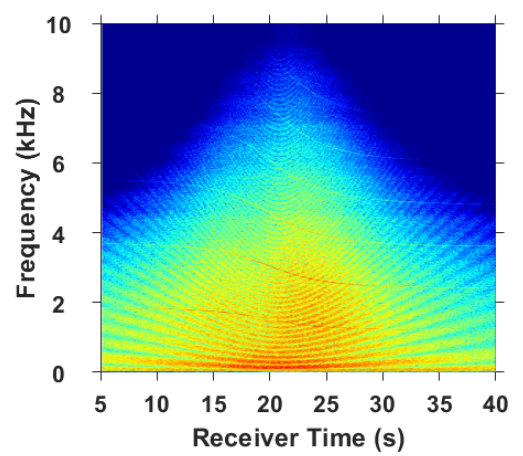

(a) NAF

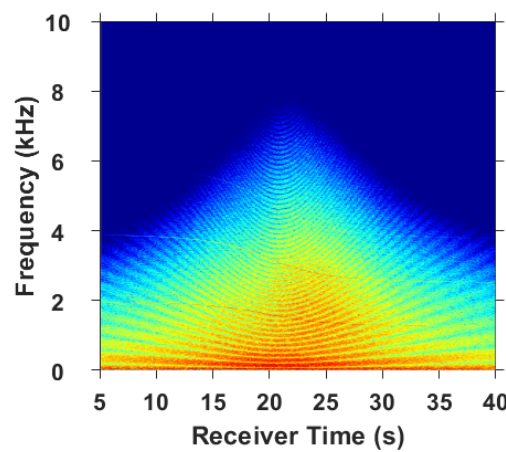

(b) AURAFONE

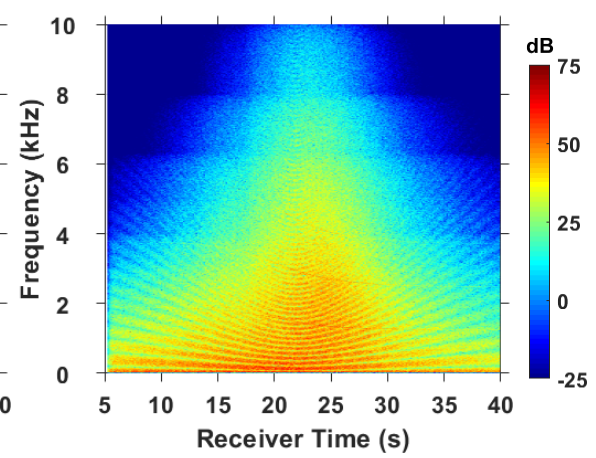

(c) FLAURA

Figure 14: Spectrograms of V-R aircraft on approach (\#5).

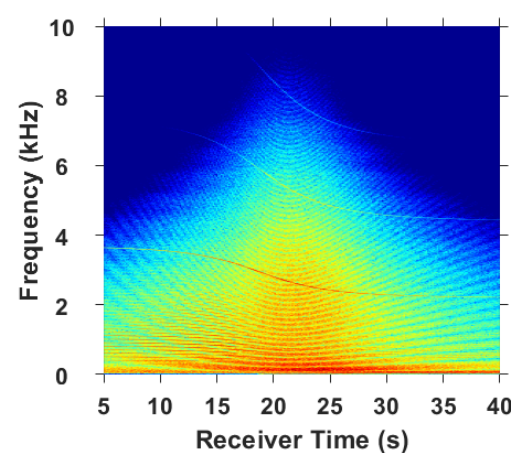

(a) NAF

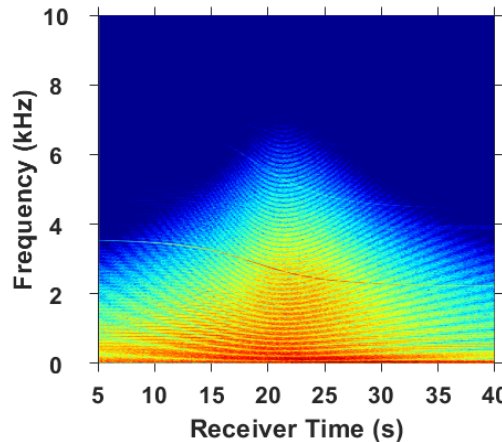

(b) AURAFONE

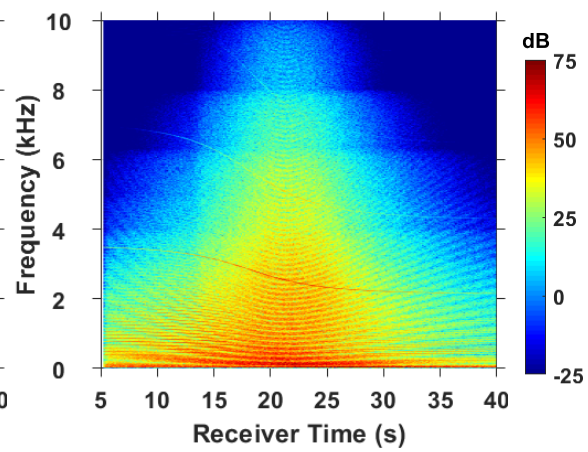

(c) FLAURA

Figure 15: Spectrograms of V-R aircraft on departure (\#6).

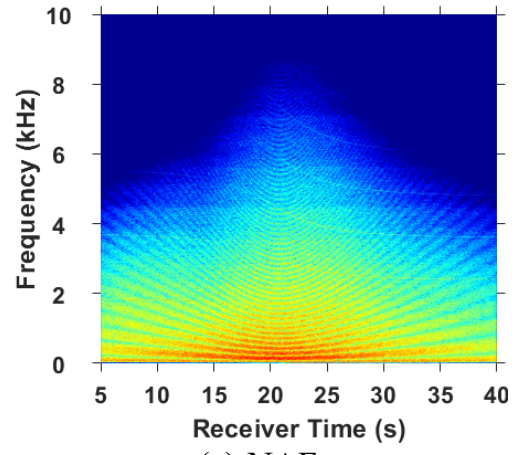

(a) NAF

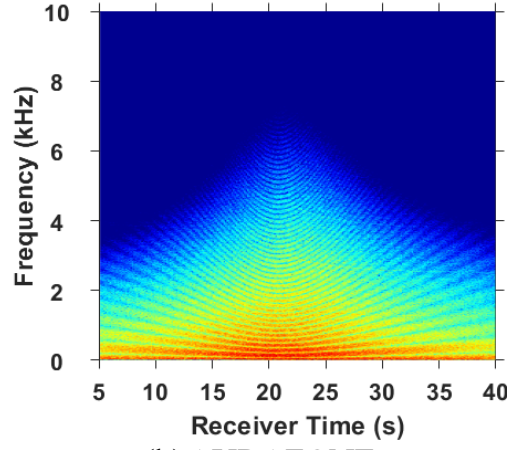

(b) AURAFONE

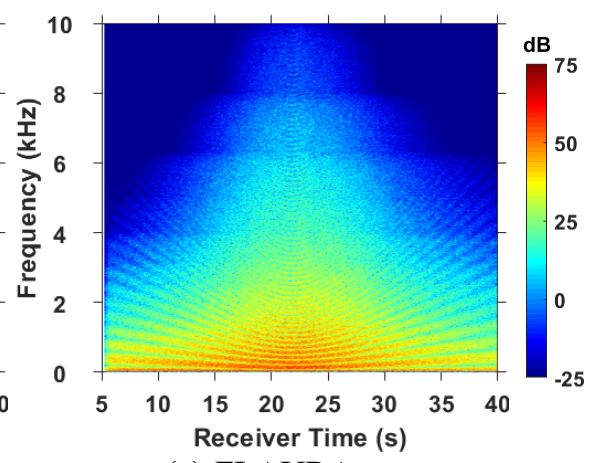

(c) FLAURA

Figure 16: Spectrograms of V-2 aircraft on approach (\#7).

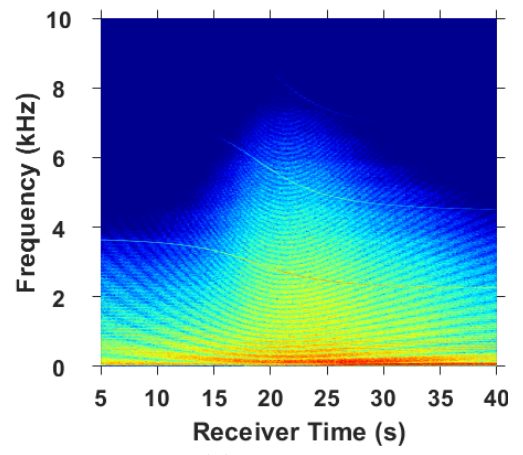

(a) NAF

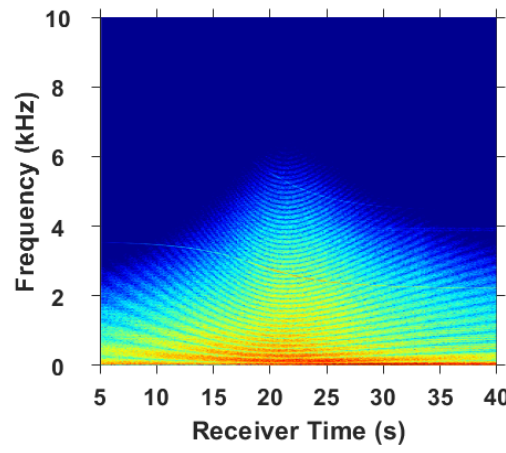

(b) AURAFONE

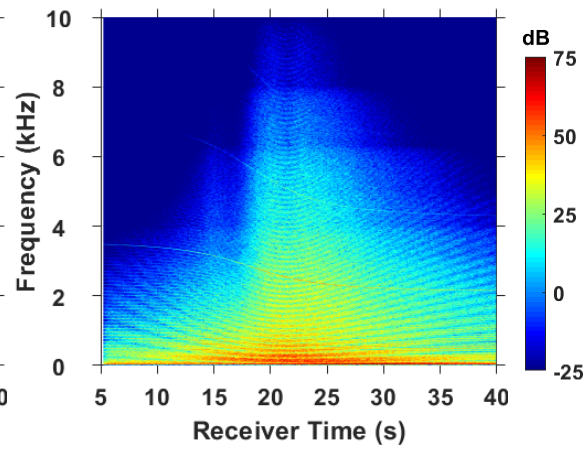

(c) FLAURA

Figure 17: Spectrograms of V-2 aircraft on departure (\#8, centerline observer). 


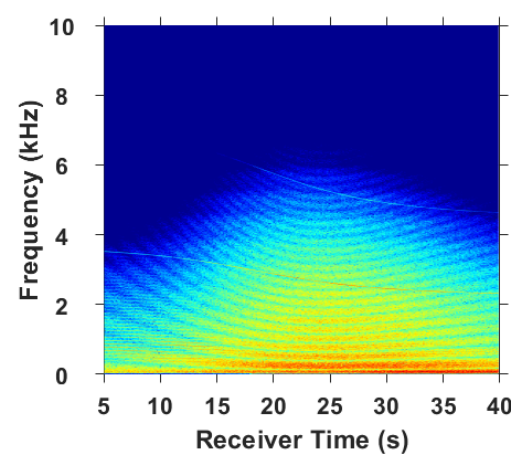

(a) NAF

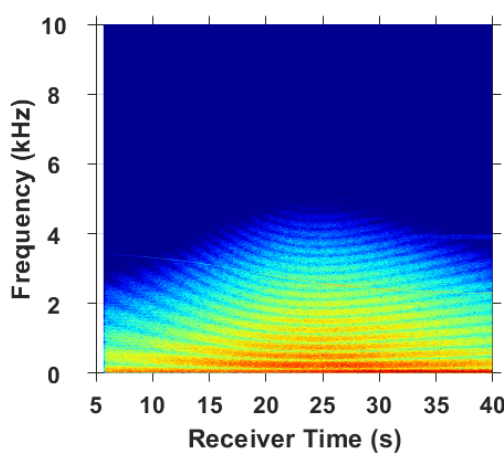

(b) AURAFONE

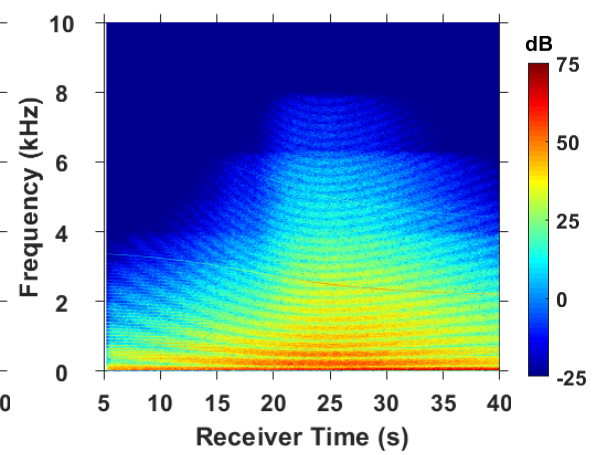

(c) FLAURA

Figure 18: Spectrograms of V-2 aircraft on departure (\#8a, sideline observer).

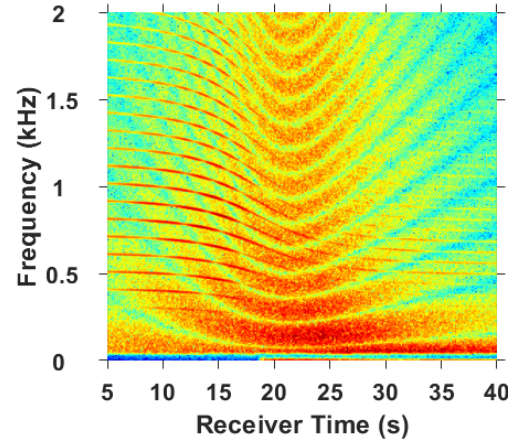

(a) NAF

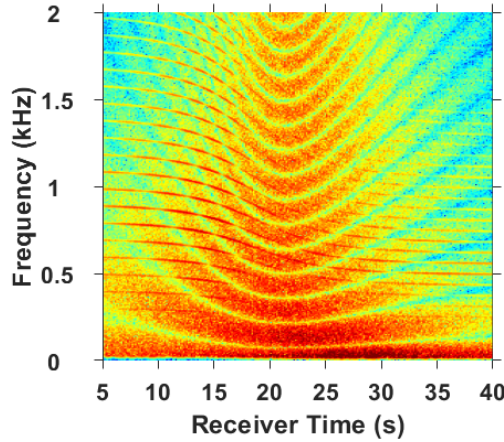

(b) AURAFONE

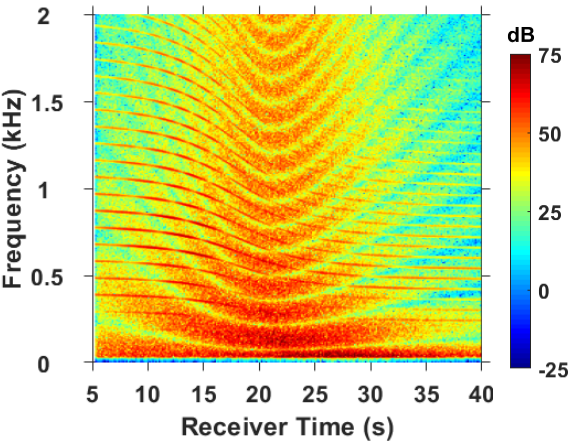

(c) FLAURA

Figure 19: Close-up of V-R aircraft spectrograms on departure (\#6).

\section{Sound Quality Metrics}

Sound quality metrics offer a quantitative measure of the qualitative indicators observed in the spectrograms and were calculated from the pseudorecordings. Loudness (N), sharpness (S), roughness, fluctuation strength, and toneto-noise ratio (TNR) metrics were calculated in the manner described in Rizzi et al. ${ }^{41}$ From the metric time histories, the $5^{\text {th }}$ percentile, that is, the value of the metric which is exceeded $5 \%$ of the measurement time, was calculated. Plotted in Figure 20 and Figure 21 are the $5^{\text {th }}$ percentiles of loudness $\left(\mathrm{N}_{5}\right)$ and sharpness $\left(\mathrm{S}_{5}\right)$ for each of the three auralization methods for each flight operation. Those for roughness and fluctuation strength were considered low and were not plotted. Doubling of the number of sones doubles the perceived loudness, so the loudest V-R case (\#6) should be perceived about twice as loud as the three V-2 cases (\#7, 8, 8a) according to this metric. It is not surprising that loudness tracks EPNL fairly well, but not perfectly. One reason for that is the lack of a tone penalty in loudness. Sharpness is an indicator of the spectral balance of an audible impression; the greater the amount of high frequency content, the greater the sharpness value. While considered of low influence in terms of the Zwicker-Fastl psychoacoustic annoyance model, ${ }^{42}$ the sharpness values in Figure 21 nevertheless reflect the higher frequency content of the FLAURA auralizations over that of the NAF and AURAFONE auralizations, in agreement with the observation in the spectrograms.

Example TNR data from case \#6 are shown in Figure 22 for the NAF auralization. The BPF of the rotor-stator interaction tone and the buzzsaw tones are pronounced, but data in this form are difficult to use for comparing one set of data with another. To that end, a more compact form as an overall single number may be obtained by first identifying all tones that are considered prominent ${ }^{43}$ (TNR $>8 \mathrm{~dB}$ ), and integrating those over time for all such tones. Lacking a standard, a duration of $10 \mathrm{~s}$ on either side of the time of maximum PNLT was chosen as it approximated the average EPNL duration over all conditions. Table 5 provides the cumulative time above $8 \mathrm{~dB}$ TNR for all auralizations and operations.

Neither approach condition $(\# 5,7)$ has TNR values above $8 \mathrm{~dB}$, for any of the auralization methods. Consequently the cumulative times above $8 \mathrm{~dB}$ are zero for these conditions. The cumulative time above for the V$\mathrm{R}$ aircraft on departure (\#6) is much greater than that of both V-2 aircraft departures (\#8, 8a). Further, the time above values for the NAF auralization of cases $\# 6$ and \#8 are more than double that of the AURAFONE and FLAURA auralizations. In an indirect way, this helps explain the high PNLT tone penalties for the NAF 
auralizations of case \#6 (Figure 10) and \#8 (Figure 12) in the first several seconds of the simulation. The time above values for case \#8a are comparable amongst auralizations.

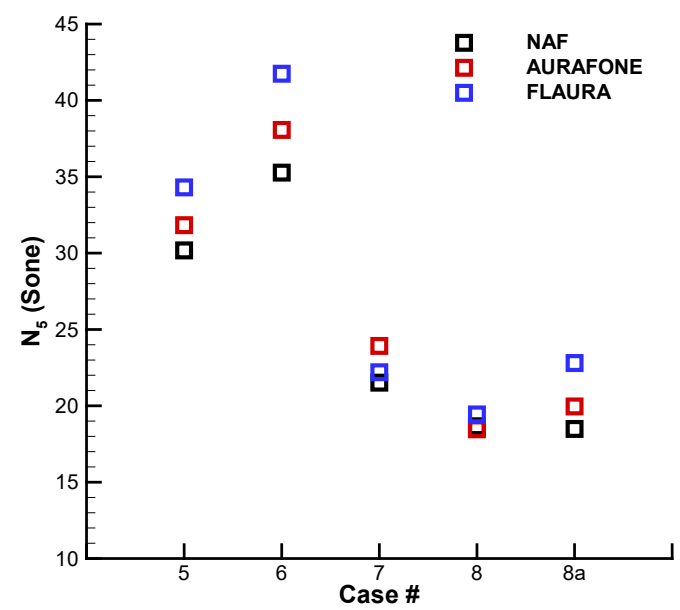

Figure 20: $5^{\text {th }}$ percentile of loudness $\left(\mathrm{N}_{5}\right)$ for each flight operation.

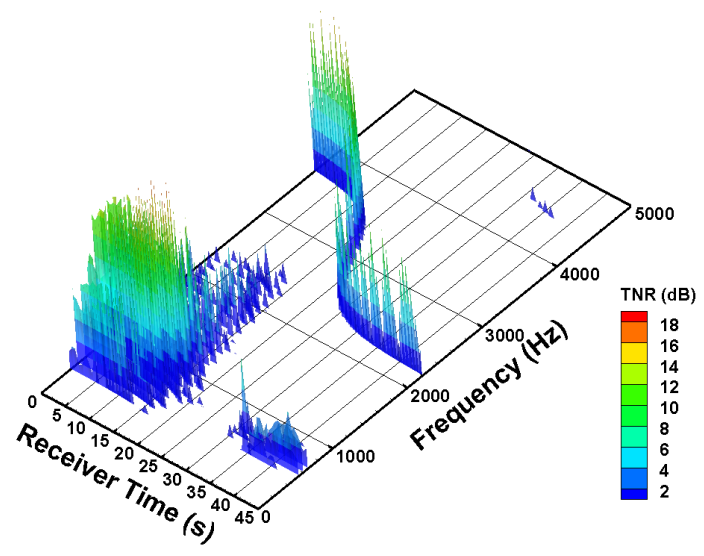

Figure 22: Tone-to-noise ratio $(\mathrm{dB})$ from NAF auralization of V-R aircraft on departure (\#6).

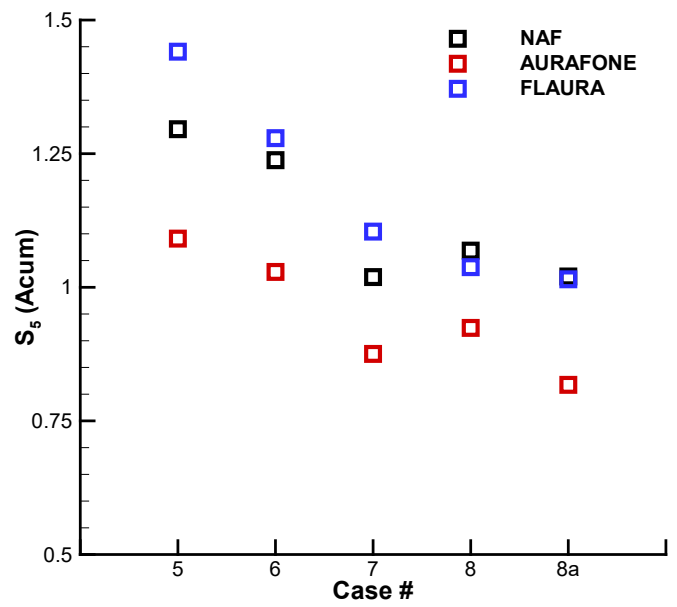

Figure 21: $5^{\text {th }}$ percentile of sharpness $\left(\mathrm{S}_{5}\right)$ for each flight operation.

Table 5: Cumulative time (s) of all tones above $8 \mathrm{~dB}$ TNR from three auralizations of each flight operation.

\begin{tabular}{cccc}
$\begin{array}{c}\text { Operation } \\
\text { /Case } \#\end{array}$ & NAF & AURAFONE & FLAURA \\
\hline $\begin{array}{c}\text { V-R app. } \\
/ 5\end{array}$ & 0 & 0 & 0 \\
\hline $\begin{array}{c}\text { V-R dep. } \\
\text { / } 6\end{array}$ & 40.3 & 17.1 & 16.4 \\
\hline $\begin{array}{c}\text { V-2 app. } \\
/ 7\end{array}$ & 0 & 0 & 0 \\
\hline $\begin{array}{c}\text { V-2 dep. } \\
/ 8\end{array}$ & 10.2 & 4.8 & 4.8 \\
\hline $\begin{array}{c}\text { V-2 dep. } \\
\text { / 8a }\end{array}$ & 5.5 & 6.1 & 4.1 \\
\hline
\end{tabular}

\section{Concluding Remarks}

Auralizations of flyover noise of two aircraft, a reference tube-and-wing configuration and a high-wing vehicle with engine installation above the fuselage-wing-junction, were performed for simplified approach and departure flight operations. The auralizations were based on system noise predictions performed under an earlier campaign, ${ }^{1,2}$ but were modified to include the effect of a finite impedance ground plane. Auralizations were generated using the NASA NAF, Empa AURAFONE, and ONERA FLAURA codes, using system noise predictions from the NASA ANOPP2, DLR PANAM, and ONERA CARMEN codes, respectively.

Attribution of differences among results was made difficult because the auralizations reflected both differences in the system noise predictions and differences in the auralization processes used. Nevertheless, use of different measures, ranging from integrated certification type metrics to sound quality metrics, allowed the source of some differences to be identified. PNLT time histories were used to identify consistencies and differences between auralizations and the system noise predictions on which they were based. Differences were attributed to the inconsistencies in propagation modeling and elevated tone penalties in high TNR auralization data. Spectrograms gave largely qualitative insight into spectral differences that were further substantiated with sound quality metrics. 
Overall, the auralizations among NASA, DLR/Empa, and ONERA compared very well. Certainly, the collaborative nature of this work helped the ANSWr participants gain a better understanding of one another's capabilities and methods used, and aided with the interpretation of results.

Going forward, there are at least two aspects of this work that remain to be addressed. First, it would be useful to perform auralizations using the three auralization tools but using the same set of source noise description data. In this manner, differences in auralizations could be attributed solely to the auralization method used, and not the combination of that and the prior system noise prediction data. Second, while the measures considered in Section IV.D helped to identify consistencies and differences among auralizations, the extent to which these are significant is unknown. For that, a paired comparison test could be used to determine the subjective similarity among auralizations.

\section{Acknowledgments}

The NASA contribution to the ANSWr collaboration was funded by the Aircraft Noise Reduction Subproject of the Advanced Air Transport Technology Project, and by the Revolutionary Tools and Methods Subproject of the Transformational Tools and Technologies Project. The funding for the DLR work package was partially supported by the Projektfoerderung zur Internationalen Zusammenarbeit and the DLR Directorate Aeronautics. The ONERA contribution to the ANSWr collaboration was funded by internal budget dedicated to international collaborations. The Empa contribution to this paper was performed as part of the European research project Aircraft noise Reduction Technologies and related Environmental iMpact (ARTEM), which has received funding from the European Union's Horizon 2020 research and innovation programme under grant agreement No. 769350.

Stephen Rizzi also wishes to acknowledge Drs. Ian Clark, Len Lopes, and Venkat Iyer for assistance with the ANOPP2 systems noise analyses, and Mr. Aric Aumann for development of a NAF component for buzzsaw noise synthesis.

\section{References}

${ }^{1}$ Bertsch, L., Thomas, R.H., Sanders, L., and LeGriffon, I., "The Aircraft Noise Simulation Working Group (ANSWr) - Tool benchmark and reference aircraft results," 25th AIAA/CEAS Aeroacoustics Conference, AIAA 2019-2539, Delft, The Netherlands, 2019, https://doi.org/10.2514/6.2019-2539.

${ }^{2}$ Sanders, L., Thomas, R.H., Bertsch, L., LeGriffon, I., Clark, I., June, J.C., and Lorteau, M., "The Aircraft Noise Simulation Working Group (ANSWr) - V2 aircraft results," 25th AIAA/CEAS Aeroacoustics Conference, AIAA 2019-2540, Delft, The Netherlands, 2019, https://doi.org/10.2514/6.2019-2540.

${ }^{3}$ Vorländer, M., Auralization - Fundamentals of acoustics, modelling, simulation, algorithms and acoustic virtual reality. Springer-Verlag, Berlin, 2008.

${ }^{4}$ Rizzi, S.A., "Toward reduced aircraft community noise impact via a perception-influenced design approach," InterNoise 2016, Hamburg, Germany, 2016, pp. 2-26.

${ }^{5}$ Bertsch, L., "Noise prediction within conceptual aircraft design," DLR Forschungsbericht, ISRN DLR-FB-2013-20, 2013, https://doi.org/10.34912/n0is3-d3sign.

${ }^{6}$ Werner-Westphal, C., Heinze, W., and Horst, P., "Multidisciplinary integrated preliminary design applied to future green aircraft configurations," 45th AIAA Aerospace Sciences Meeting and Exhibit, AIAA-2007-655, 2007, https://doi.org/10.2514/6.2007-655.

${ }^{7}$ Deidewig, F., "Ermittlung der Schadstoffemissionen im Unter- und Ueberschallflug (in German)," DLR Forschungsbericht 98-10, Cologne, Germany, 1998.

${ }^{8}$ Lopes, L.V. and Burley, C.L., "ANOPP2 user's manual: version 1.2," NASA TM-2016-219342, 2016.

${ }^{9}$ Zorumski, W.E., "Aircraft noise prediction program theoretical manual," NASA TM-83199, 1982.

${ }^{10}$ Malbéqui, P., Rozenberg, Y., and Bulté, J., "Aircraft noise modelling and assessment in the IESTA program," InterNoise 2011, Osaka, Japan, 2011.

${ }^{11}$ Brunet, M., Chaboud, T., Huynh, N., Malbequi, P., and Ghedhaifi, W., "Environmental impact evaluation of air transport systems through physical modeling and simulation," 9th AIAA Aviation Technology, Integration, and Operations Conference (ATIO), AIAA 2009-6936, Hilton Head, SC, 2009, https://doi.org/10.2514/6.2009-6936.

${ }^{12}$ Thomas, R.H., Burley, C.L., and Nickol, C.L., "Assessment of the noise reduction potential of advanced subsonic transport concepts for NASA's Environmentally Responsible Aviation Project," 54th AIAA Aerospace Sciences Meeting, AIAA-2016-0863, San Diego, CA, 2016, https://doi.org/10.2514/6.2016-0863. 
${ }^{13}$ Thomas, R.H. and Guo, Y., "Ground noise contour prediction for a NASA hybrid wing body subsonic transport aircraft," 23rd AIAA/CEAS Aeroacoustics Conference, AIAA-2017-3194, Denver, CO, 2017, https://doi.org/10.2514/6.2017-3194.

${ }^{14}$ Guo, Y., Pope, D.S., Burley, C.L., and Thomas, R.H., "Aircraft system noise shielding prediction with a Kirchhoff integral method," 23rd AIAA/CEAS Aeroacoustics Conference, AIAA-2017-3196, Denver, CO, 2017, https://doi.org/10.2514/6.2017-3196.

${ }^{15}$ June, J.C., Thomas, R.H., and Guo, Y., "System noise prediction uncertainty quantification for a hybrid wingbody transport concept," AIAA Journal, Vol. 58, No. 3, 2020, pp. 1157-1170, https://doi.org/10.2514/1.J058226.

${ }^{16} \mathrm{Schmid}$, R., "Half-empirical, physical model for the directional characteristic of sound radiated by modern turbofan engines (Doctoral thesis)," University of Göttingen, Germany, 2000.

${ }^{17}$ Dobrzynski, W., Chow, L., Guion, P., and Shiells, D., "A European study on landing gear airframe noise sources," 6th Aeroacoustics Conference, AIAA-2000-1971, Lahaina, HI, 2000, https://doi.org/10.2514/6.2000-1971.

${ }^{18}$ Dobrzynski, W. and Pott-Pollenske, M., "Slat noise source studies for farfield noise prediction," 7 th AIAA/CEAS Aeroacoustics Conference, AIAA 2001-2158, Maastricht, The Netherlands, 2001, https://doi.org/10.2514/6.2001-2158.

${ }^{19}$ Lummer, M., Hepperle, M., and Delfs, J., "Towards a tool for the noise assessment of aircraft configurations, aeroacoustics of new aircraft and engine configurations," 8th ASC-CEAS Workshop, Budapest, Hungary, 2004.

${ }^{20}$ Lummer, M., "Maggi-Rubinowicz diffraction correction for ray-tracing calculations of engine noise shielding," 14th AIAA/CEAS Aeroacoustics Conference (29th AIAA Aeroacoustics Conference), AIAA 2008-3050, Vancouver, British Columbia, Canada, 2008, https://doi.org/10.2514/6.2008-3050.

21 "Method for the calculation of the absorption of sound by the atmosphere," Americal National Standards Institute, Inc., ANSI/ASA S1.26-2014, 2014.

22"Acoustics - Attenuation of sound during propagation outdoors - Part 1: Calculation of the absorption of sound by the atmosphere," International Organization for Standardization, ISO 9613-1:1993, 1993.

${ }^{23}$ Chien, C.F. and Soroka, W.W., "Sound propagation along an impedance plane," Journal of Sound and Vibration, Vol. 43, No. 1, 1975, pp. 9-20, https://doi.org/10.1016/0022-460X(75)90200-X.

24"Prediction method for lateral attenuation of airplane noise during takeoff and landing," SAE International, SAE AIR1751, 1991.

${ }^{25}$ Delany, M.E. and Bazley, E.N., "Acoustical properties of fibrous absorbent materials," Applied Acoustics, Vol. 3, No. 2, April 1970, pp. 105-116, http://dx.doi.org/10.1016/0003-682X(70)90031-9.

26"Annex 16 to the Convention on International Civil Aviation, Environmental Protection, Volume I, Aircraft Noise (7th Edition)," International Civil Aviation Organization, Montreal, Canada, July, 2014.

${ }^{27}$ Rizzi, S.A. and Sahai, A.K., "Auralization of air vehicle noise for community noise assessment," CEAS Aeronautical Journal, Vol. 10, No. 1, 2019, pp. 313-334, https://doi.org/10.1007/s13272-019-00373-6.

${ }^{28}$ Aumann, A.R., Tuttle, B.C., Chapin, W.L., and Rizzi, S.A., "The NASA Auralization Framework and plugin architecture," InterNoise 2015, San Francisco, CA, 2015.

${ }^{29}$ Tuttle, B.C., Aumann, A.R., Rizzi, S.A., Jones, J., and Lopes, L.V., "Flyover noise simulation using NASA's coupled aircraft system noise prediction and auralization frameworks," Noise-Con 2017, Paper 347, Grand Rapids, 2017.

${ }^{30}$ Rizzi, S.A., Aumann, A.R., Lopes, L.V., and Burley, C.L., "Auralization of hybrid wing-body aircraft flyover noise from system noise predictions," AIAA Journal of Aircraft, Vol. 51, No. 6, 2014, pp. 1914-1926, https://doi.org/10.2514/1.C032572.

${ }^{31}$ Rizzi, S.A., Sullivan, B.M., and Aumann, A.R., "Recent developments in aircraft flyover noise simulation at NASA Langley Research Center," NATO Research and Technology Agency AVT-158 "Environmental Noise Issues Associated with Gas Turbine Powered Military Vehicles" Specialists' Meeting, Paper 17, Montreal, Canada, 2008, NATO RTA Applied Vehicle Technology Panel pp. 14.

${ }^{32}$ Pieren, R., Heutschi, K., Müller, M., Manyoky, M., and Eggenschwiler, K., "Auralization of wind turbine noise: emission synthesis," Acta Acustica united with Acustica, Vol. 100, No. 1, 2014, pp. 25-33, https://doi.org/10.3813/AAA.918683.

${ }^{33}$ Pieren, R., Bütler, T., and Heutschi, K., "Auralization of accelerating passenger cars using spectral modeling synthesis," Applied Sciences, Vol. 6(1), No. 5, 2016, pp. 1-27, https://doi.org/10.3390/app6010005.

${ }^{34}$ Pieren, R., Heutschi, K., Wunderli, J.M., Snellen, M., and Simons, D.G., "Auralization of railway noise: emission synthesis of rolling and impact noise," Applied Acoustics, Vol. 127, 2017, pp. 34-45, https://doi.org/10.1016/j.apacoust.2017.05.026. 
${ }^{35}$ Pieren, R., Bertsch, L., Blinstrub, J., Schäffer, B., and Wunderli, J.M., "Simulation process for perception-based noise optimization of conventional and novel aircraft concepts," AIAA SciTech 2018, AIAA-2018-0266, 2018, https://doi.org/10.2514/6.2018-0266.

${ }^{36}$ Pieren, R., Bertsch, L., Lauper, D., and Schäffer, B., "Improving future low-noise aircraft technologies using experimental perception-based evaluation of synthetic flyovers," Science of The Total Environment, Vol. 692, 2019, https://doi.org/10.1016/j.scitotenv.2019.07.253.

${ }^{37}$ Zölzer, U., ed. DAFX - Digital audio effects. John Wiley \& Sons, Ltd., West Sussex, England, 2002.

${ }^{38}$ Allen, M.P., Rizzi, S.A., Burdisso, R., and Okcu, S., "Analysis and synthesis of tonal aircraft noise sources," 18th AIAA/CEAS Aeroacoustics Conference (33rd AIAA Aeroacoustics Conference), AIAA-2012-2078, Colorado Springs, CO, 2012, https://doi.org/10.2514/6.2012-2078.

${ }^{39} \mathrm{https}: / /$ stabserv.larc.nasa.gov/flyover/, NASA, 2020.

40"Method for predicting lateral attenuation of airplane noise," SAE International, SAE AIR5662, 2019.

${ }^{41}$ Rizzi, S.A., Burley, C.L., and Thomas, R.H., "Auralization of NASA N+2 aircraft concepts from system noise predictions," 22nd AIAA/CEAS Aeroacoustics Conference, AIAA 2016-2906, Lyon, France, 2016, https://doi.org/10.2514/6.2016-2906.

${ }^{42}$ Zwicker, E. and Fastl, H. Second ed, Psychoacoustics, Facts and Models, ed. M.R. Schroeder. Springer-Verlag, Berlin, 1999.

43"Measurement of airborne noise emitted by information technology and telecommunications equipment," ECMA International, ECMA-74 10th Edition, 2008. 